\title{
Steady-State Steering Characteristics of Mathematical Model for Semitrailer Based on Variations in Camber Parameters
}

\author{
Yi Wei, ${ }^{1,2}$ Shuilong He $\mathbb{D},{ }^{1,3}$ Enyong Xu, ${ }^{3}$ Genge Zhang, ${ }^{2}$ Rongjiang Tang $\mathbb{D},{ }^{1}$ Wei Wang, ${ }^{3}$ \\ and $\mathrm{Chao} \mathrm{Li}^{3}$ \\ ${ }^{1}$ School of Mechanical and Electrical Engineering, Guilin University of Electronic Technology, Guilin 541004, China \\ ${ }^{2}$ Transportation College of Nanning University, Nanning 530299, China \\ ${ }^{3}$ Dongfeng Liuzhou Motor Co., Ltd., Liuzhou 545005, China \\ Correspondence should be addressed to Shuilong He; xiaofeilonghe@163.com and Rongjiang Tang; 251444972@qq.com
}

Received 17 February 2020; Revised 30 April 2020; Accepted 25 May 2020; Published 13 June 2020

Academic Editor: Yanxue Wang

Copyright ( 2020 Yi Wei et al. This is an open access article distributed under the Creative Commons Attribution License, which permits unrestricted use, distribution, and reproduction in any medium, provided the original work is properly cited.

To master the basic characteristics of steady-state cornering for a semitrailer, this paper summarises the current modelling methods for handling and stability and discusses their limitations. The classical linear mathematical model for a two-degree-offreedom (DOF) handling and stability system is used to develop a new model. Analysis methods are proposed to introduce the influence of the camber angle and body roll into the model parameters. Thus, a mathematical model for the lateral stability of semitrailer with five DOFs is established. At the same time, a modified formula to calculate the stability factor of the semitrailer is developed with a MATLAB model to solve the dynamic state equation. The mathematical model, which considers the body roll and the changes in the camber angle caused by roll, compares the turning radius ratio and yaw rate as the evaluation index with the classical linear mathematical model of a two-DOF system. The vehicle parameters for three different types of semi-tractor trailers are used to calculate and compare two mathematical models for handling and stability using real vehicle test data. The results show that the new modelling and analysis method proposed in this paper has a high calculation accuracy and fast calculation speed, is clear and concise, and is consistent with the real vehicle test data. In addition, the accuracy of the new mathematical model for handling and stability and the improved stability factor are verified.

\section{Introduction}

The handling and stability of vehicles is its ability to drive according to the driver's intention. Semitrailer and other articulated vehicles are complex dynamic systems with the coupling effects of the tractor and the trailer. The research for the handling and stability of vehicles is to maintain the vehicle trajectory and control its yaw [1-3]. To date, theoretical research on vehicle handling and stability is primarily through the establishment of mathematical models. Highprecision dynamics models for vehicle handling and stability are of great importance for system performance analyses and the development of stability controllers $[4,5]$.

At present, some achievements have been made in the theoretical research on the steady-state steering characteristics of semitrailer.: $\mathrm{Wu}$ [6] established a five-degree-of- freedom- (DOF-) articulated vehicle using a multisteering mathematical model. The basic analytical results of the yaw/ roll performance characteristics were presented, and the effects of the roll steer about the lateral force under steadystate turning were discussed and illustrated. The mathematical model considered the influence of roll on the steadystate steering, but it did not account for the influence of the camber angle of the tire as caused by roll, suggesting their model has some limitations. Kobayashi et al. [7] constructed a new formula of the mechanism by which direct yaw moments alter the cornering resistance and mechanical power for all wheels based on the classical mathematical model of a two-DOF system. This includes the electric loss of the motors and the inverter to study the steady-state steering characteristics of the vehicle. However, the influence of roll on the wheel deflection characteristics is not considered in 
the new formulation. Sankar and Surial [8] proposed a mathematical sensitivity method to study the effects of variations in parameters on the rollover stability of heavy articulated vehicles during steady turning manoeuvres. The results show that their approach provides a quick and accurate estimate of the vehicle rollover response to reasonable variations in the parameters. However, the influence of tire characteristics on the steady-state steering under roll conditions was not considered. Zhang et al. [9] proposed an analytical lateral dynamic model for skid steering with a wheeled vehicle that could be applied to its design and control. The model is described using second-order ordinary differential equations in an explicit form, and the steady-state characteristics of skid steering for wheeled vehicles were analysed based on differential equations. While the analysis results showed that the steady-state response of the skid-steered wheeled vehicle is determined from the stability factor, the influences of this factor were not given. Hussain et al. [10] established a multidegree-of-freedom, nonlinear, multibody, dynamic model for semitrailer handling and stability. The model incorporates all sources of compliance, stiffness, and damping, all of which have nonlinear characteristics. The model was used primarily to study the rollover stability of an articulated vehicle; however, under roll conditions, the rollover model does not consider the influence of changes in the tire characteristics.

The steady-state steering characteristics of vehicles have been studied using a variety of methods, but the influence of changes in the camber angle of the tires as caused by roll was not considered in previous mathematical models. However, it is important to establish a model for the entire vehicle. A more complex correlation for expressions in such a model is not necessarily better, as the mechanism of the key factors should be considered. One of the key factors in the mathematical model for handling and stability is the tire characteristics, where the body roll of the vehicle can cause changes to the camber and toe angles, while the influence on the tire cornering characteristics is relatively large.

This paper presents an established mathematical model for the manoeuvring stability of a vehicle based on the linear mathematical model with two DOFs. To improve the accuracy of the steady-state model for the vehicle steering stability, the influence of the camber angle caused by roll and body roll into the model parameters is proposed. A mathematical model for the lateral stability of a semitrailer with five DOFs is established. Finally, the evaluation indices of the yaw velocity and the turning radius ratio as well as experiments are used to verify the theoretical model. Compared with the traditional linear, two-DOF, mathematical model, the proposed model more accurately reflects the vehicle ground state under steady-state steering conditions.

This article is divided into the following sections. Section 2 discusses the shortcomings of the traditional two-DOF mathematical model and proposes a new method to calculate the stability factor through the introduction of tire inclination parameters. Section 3 verifies the accuracy of the introduced tire inclination parameter model based on the evaluation index of the yaw velocity. Section 4 verifies the accuracy of the calculation method based on the evaluation index of the turning radius ratio. Section 5 gives the conclusions of the study.

\section{Mathematical Model of Vehicle Handling and Stability}

The proposed mathematical model for handling and stability is introduced, which considers the continual influence of the camber angle as caused by roll and body roll. A modified formula to calculate the stability factor of a semitrailer is given.

2.1. Principle of Model Simplification. In general, the dynamic characteristics of semitrailer are much more complex than those of a truck. These primarily involve the relative motion between the tractor and trailer and the coupling effects between the traction seat and the traction pin of semitrailer [11-13]. To study the dynamic characteristics of a semitrailer, the following aspects are simplified in the semitrailer model due to combining automobile theory with multibody dynamics:

(i) The tractor and trailer are regarded as rigid bodies, and the semitrailer trains are regarded as a combination of two rigid bodies connected via the coupling of a traction pin and traction seat

(ii) The roll and yaw motions of the semitrailer train are considered while the vertical and pitching motions are not

(iii) In the analysis of the force for the semitrailer train system, the rolling and air resistances are neglected

(iv) In the analysis of the side deflection force of the tires, the side deflection angles of the left and right tires are assumed to be equal and relatively small, and the front wheel angle of the tire is also considered to be relatively small

Based on the above simplifications, the semitrailer train can be simplified using a monorail and double centroid model $[12,14,15]$ with five DOFs. The DOFs are the lateral motion $y$, yaw motion $r$, roll angle of the tractor and trailer $\varphi$, steering angle $\delta$, and folding angles between the tractor and trailer $\theta$. A more realistic open-loop research method is adopted, as shown in Figure 1.

2.2. Classical Mathematical Model of a Two-DOF System. The mathematical model for the classical two-DOF system only considers the side angles of the front and rear tires. The lateral forces for each axle tire are given as

$$
\left\{\begin{array}{l}
F_{Y_{1}}=k_{1} \alpha_{1}, \\
F_{Y_{2}}=k_{2} \alpha_{2}, \\
F_{Y_{3}}=k_{3} \alpha_{3},
\end{array}\right.
$$

where $k_{1}, k_{2}$, and $k_{3}$ are the lateral deflection angle stiffnesses for the front, middle, and rear axles of the tire, respectively $(\mathrm{N} / \mathrm{rad})$, and $\alpha_{1}, \alpha_{2}$, and $\alpha_{3}$ are the tire sideslip angles of the front, middle, and rear axles of the tire, respectively (rad). The differential equations of motion for the tractor and trailer are given as follows: 


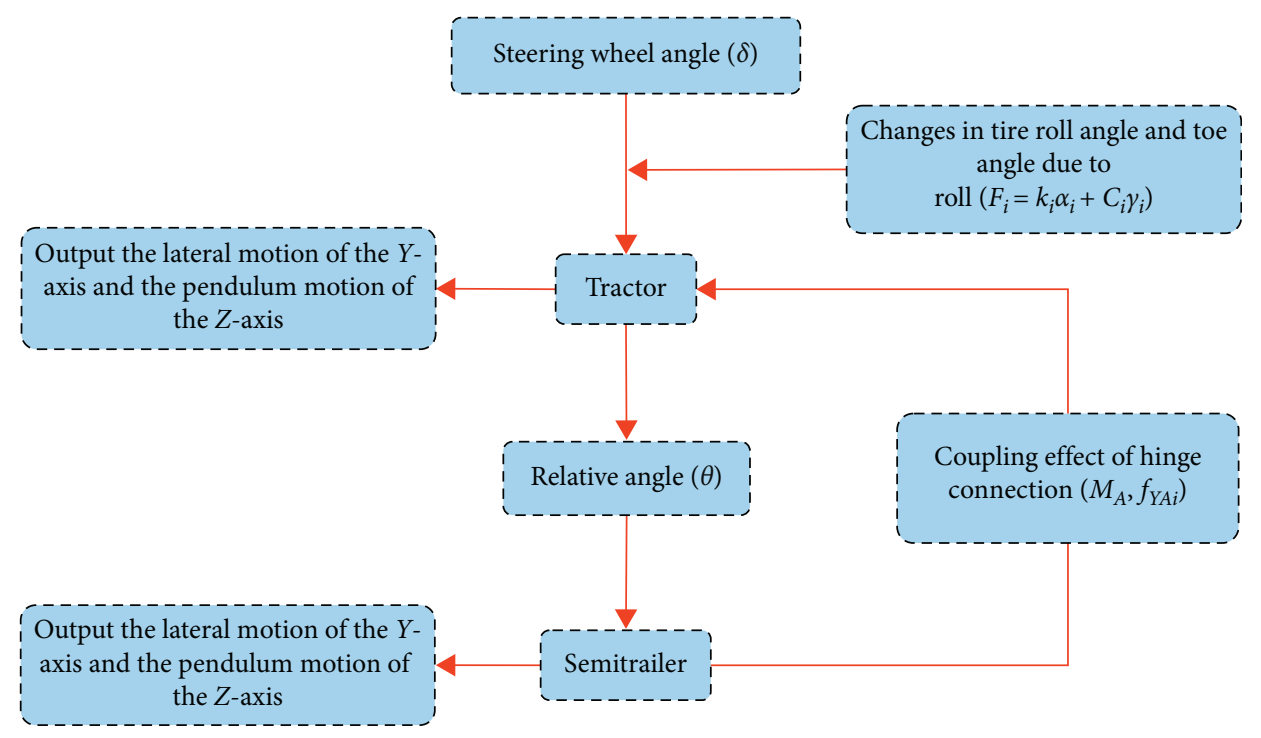

FIgure 1: Schematic diagram of the modelling method.

$$
\left\{\begin{array}{l}
{\left[m_{1}\left(\dot{\beta_{1}}+\omega_{r_{1}}\right)+m_{2}\left(\dot{\beta_{2}}+\omega_{r_{2}}\right)\right] u=F_{Y_{1}}+F_{Y_{2}}+F_{Y_{3}},} \\
I_{z_{1}} \dot{\omega}_{r_{1}}=a F_{Y_{1}}-b F_{Y_{2}}-c\left[m_{1}\left(\dot{\beta}_{1}+\omega_{r_{1}}\right) u-F_{Y_{1}}+F_{Y_{2}}\right]-M_{A}, \\
I_{z_{2}} \dot{\omega}_{r_{2}}=M_{A}-b_{1} F_{Y_{3}}-a_{1}\left[m_{1}\left(\dot{\beta}_{1}+\omega_{r_{1}}\right) u-F_{Y_{1}}+F_{Y_{2}}\right] .
\end{array}\right.
$$

When the vehicle is driving at a constant speed, the system enters the steady state, and the stability factors $K_{1}$ and $K_{2}$ can be obtained from the $k_{1}$ and $k_{2}$ in equations (2). The stability factor is an important parameter to characterise the steady state response of the vehicle as

$$
\left\{\begin{array}{l}
K_{1}=\frac{m_{1}}{L_{1}}\left(\frac{b}{k_{1}}-\frac{a}{k_{2}}\right)+\frac{m_{2}}{L_{2}} \cdot \frac{b}{L_{1}}\left(\frac{b-c}{k_{1}}-\frac{a+c}{k_{2}}\right), \\
K_{2}=\frac{m_{1}}{L_{1}} \frac{a}{k_{2}}+\frac{m_{2}}{L_{2}}\left(\frac{a+c}{L_{1}} \cdot \frac{b_{1}}{k_{2}}-\frac{a_{2}}{k_{3}}\right) .
\end{array}\right.
$$

However, the stability factor obtained from the mathematical model for the classical two-DOF is not sufficiently accurate, and its influence factor is not comprehensive. Although this approach reflects the relationship between the most basic parameters of an automobile and the stability of its handling, it ignores the influence of changes in the tire inclination angle. Such changes significantly influence the tire force and lateral angle to vary the direction of tire movement, which greatly affects the stability of vehicle handling.

\subsection{Mathematical Model considering the Camber Angle.} Changes in the camber and toe angles of the tire are affected by body roll, which manifest as the yaw rate response of the semitrailer train and affect the steering stability of the entire vehicle [2, 16-18]. The influence of the body roll under steering conditions is considered here. Variations in the camber angle under the same lateral force are introduced into the model parameter as the influence factor, as shown in Figure 2. The force analysis in Figure 2 is based on Newton's Second Law and assumes that the velocity along the $x$-axis remains unchanged while the longitudinal velocity of the centre of mass is equal; that is, $u=u_{1}$. The differential equations of motion for the tractor and trailer are obtained as follows [19]:

$$
\left\{\begin{array}{l}
m_{1}\left(\dot{\beta_{1}}+\omega_{r_{1}}\right) u=F_{Y_{1}} \cos \delta+F_{Y_{2}}+f_{Y A 1}, \\
m_{2}\left(\dot{\beta_{2}}+\omega_{r_{2}}\right) u=F_{Y_{3}}-f_{Y A 2} \\
I_{z_{1}} \dot{\omega}_{r_{1}}=a F_{Y_{1}}-b F_{Y_{2}}-c f_{Y A 1}-M_{A} \\
I_{z_{2}} \dot{\omega}_{r_{2}}=M_{A}-b_{1} F_{Y 3}-a_{1} f_{Y A 2} .
\end{array}\right.
$$

The lateral forces at traction pin $A$ from the tractor and the trailer are equal; that is, $f_{Y A 1}=f_{Y A 2}$, and the angle of the front wheel of the tire is small (the simplification $\cos \delta=1$ is made). These two conditions are brought into equations (1) to obtain

$$
\left\{\begin{array}{l}
{\left[m_{1}\left(\dot{\beta}_{1}+\omega_{r_{1}}\right)+m_{2}\left(\dot{\beta}_{2}+\omega_{r_{2}}\right)\right] u=F_{Y_{1}}+F_{Y_{2}}+F_{Y_{3}},} \\
I_{z_{1}} \dot{\omega}_{r_{1}}=a F_{Y_{1}}-b F_{Y_{2}}-c\left[m_{1}\left(\dot{\beta}_{1}+\omega_{r_{1}}\right) u-F_{Y_{1}}+F_{Y_{2}}\right]-M_{A}, \\
I_{z_{2}} \dot{\omega}_{r_{2}}=M_{A}-b_{1} F_{Y_{3}}-a_{1}\left[m_{1}\left(\dot{\beta}_{1}+\omega_{r_{1}}\right) u-F_{Y_{1}}+F_{Y_{2}}\right],
\end{array}\right.
$$

where $m_{1}$ and $m_{2}$ are the qualities for the tractor and trailer, respectively $(\mathrm{kg}) ; u$ is the longitudinal velocity of the vehicle $(\mathrm{m} / \mathrm{s}) ; I_{z_{1}}$ and $I_{z_{2}}$ are the yaw moments of inertia for the tractor and trailer, respectively $\left(\mathrm{kg} \cdot \mathrm{m}^{2}\right) ; a$ is the distance from the tractor centroid to the front axle $(\mathrm{m}) ; b$ is the distance from the tractor centroid to the middle axle (m); $a_{1}$ is the distance from the trailer centroid to the hinged point $(\mathrm{m}) ; b_{1}$ is the distance from the trailer centroid to rear axle $(\mathrm{m}) ; c$ is the distance from the tractor centroid to the hinged point (m); $L_{1}$ and $L_{2}$ are the wheelbases for the tractor and 


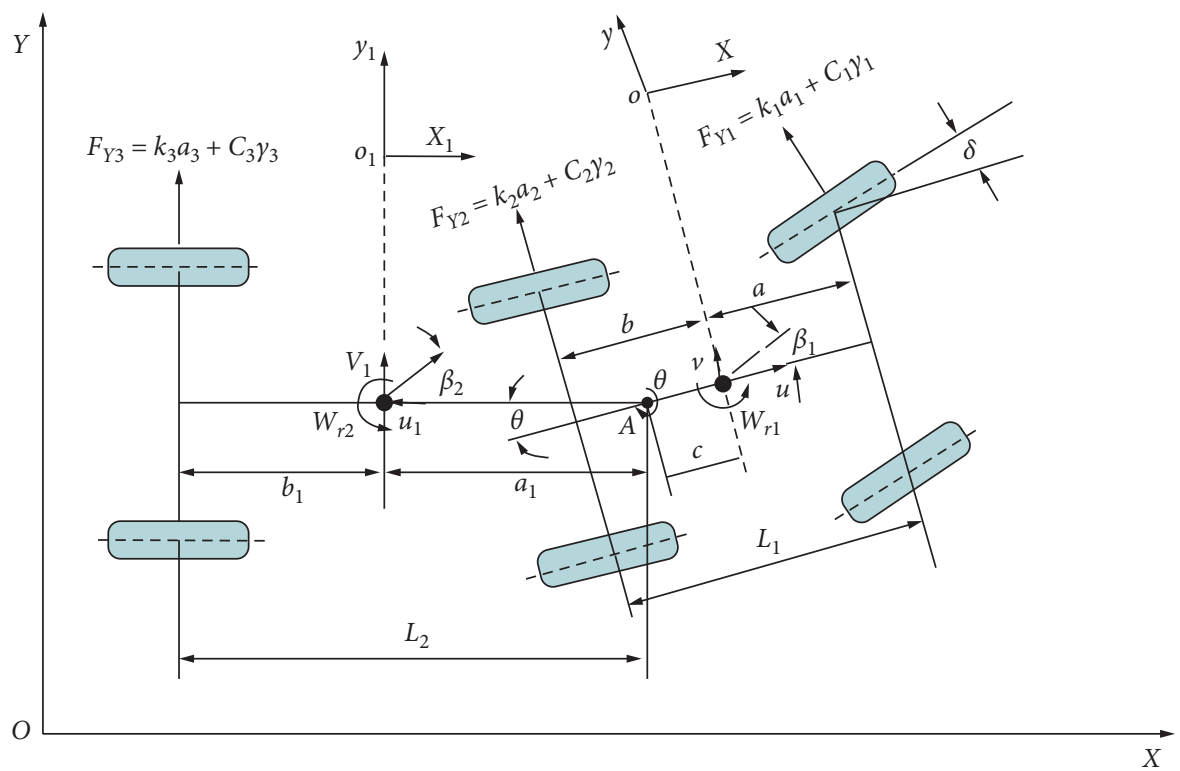

(a)

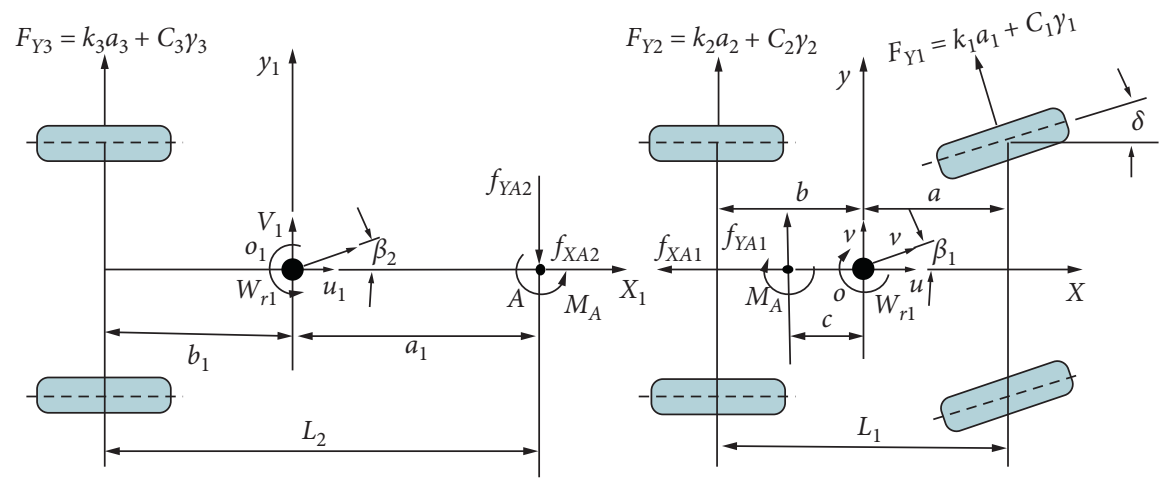

(b)

FIgUre 2: Mechanical model of the complete vehicle system. (a) Model of the motion state. (b) Model of the separation state.

trailer, respectively $(\mathrm{m}) ; \omega_{r_{1}}$ and $\omega_{r_{2}}$ are the yaw rates of the tractor and trailer centroids, respectively $(\mathrm{rad} / \mathrm{s}) ; \beta_{1}$ and $\beta_{2}$ are the sideslip angles of the tractor and trailer centroids, respectively (degree); and $F_{Y_{1}}, F_{Y_{2}}$, and $F_{Y_{3}}$ are the lateral forces of the front, middle, and rear axle of the tire, respectively $(\mathrm{N})$.

From Figure 2, the equations for tire lateral deflection angle on each axle are

$$
\left\{\begin{array}{l}
\alpha_{1}=\delta-\beta_{1}-\frac{a \omega_{r_{1}}}{u}, \\
\alpha_{2}=-\beta_{1}-\frac{b \omega_{r_{1}}}{u}, \\
\alpha_{3}=-\theta-\beta_{1}+\frac{c \omega_{r_{1}}}{u}+\frac{\left(a_{1}+b_{1}\right) \omega_{r_{2}}}{u},
\end{array}\right.
$$

where $\delta$ is the angle of the front wheel of the tractor ( $\mathrm{rad}$ ) and $\theta$ is the relative angle between the tractor and the trailer (rad).
In the classical two-DOF model, the lateral force of the tire only considers the force caused by lateral deviations. However, the proposed mathematical model also considers the lateral force caused by changes in the camber angle for the force analysis of the tires. The influence of body roll on the tire force and changes in the camber angle are introduced into the model parameters. When the wheel is steering, the outer wheel camber angle changes in the positive direction, and the inner wheel camber angle changes in the negative direction. This weakens the ability of the tire to carry the lateral force and affects the understeering of the vehicle [20], as shown in Figure 3. The equations of tire lateral forces for each axle are

$$
\left\{\begin{array}{l}
F_{Y_{1}}=k_{1} \alpha_{1}+C_{1} \gamma_{1}, \\
F_{Y_{2}}=k_{2} \alpha_{2}+C_{2} \gamma_{2}, \\
F_{Y_{3}}=k_{3} \alpha_{3}+C_{3} \gamma_{3},
\end{array}\right.
$$

where $C_{1}, C_{2}$, and $C_{3}$ are the camber angle stiffnesses of the front, middle, and rear axle tires, respectively $(\mathrm{N} / \mathrm{rad})$, and 


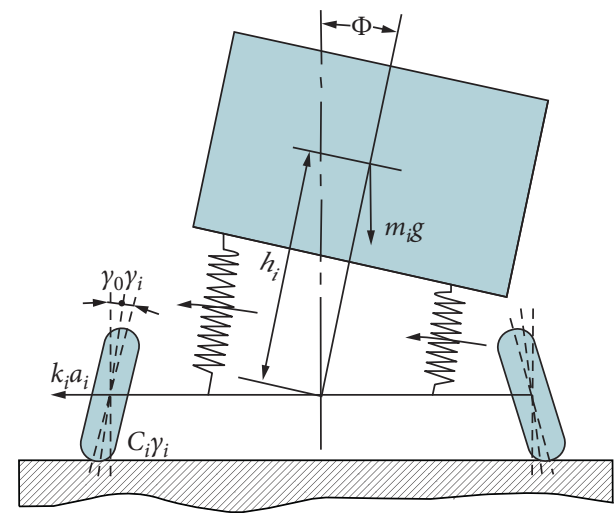

Figure 3: Force analysis diagram under steering conditions.

$\gamma_{1}, \gamma_{2}$, and $\gamma_{3}$ are the camber angles for the front, middle, and rear axle as caused by body roll, respectively (rad).

Under steady steering conditions, the body tilting moment and the lateral force of each wheel can be calculated using

$$
\left\{\begin{array}{l}
F_{Y_{1}}=\frac{b}{L_{1}} m a_{Y_{1}}=\frac{b m u \omega_{r_{1}}}{L_{1}}, \\
F_{Y_{2}}=\frac{a}{L_{1}} m a_{Y_{1}}=\frac{a m u \omega_{r_{1}}}{L_{1}}, \\
M_{\phi_{1}}=m a_{Y_{1}} h_{1}=m u \omega_{r_{1}} h_{1}, \\
F_{Y_{3}}=\frac{a_{1}}{L_{2}} m a_{Y_{2}}=\frac{a_{1} m u \omega_{r_{2}}}{L_{2}}, \\
M_{\phi_{2}}=m a_{Y_{2}} h_{2}=m u \omega_{r_{2}} h_{2},
\end{array}\right.
$$

where $M_{\phi_{1}}$ and $M_{\phi_{2}}$ are the roll torques of the tractor and trailer, respectively; $h_{1}$ and $h_{2}$ are the heights of the tractor and trailer centroids, respectively (m); and $a_{Y_{1}}$ and $a_{Y_{2}}$ are the lateral accelerations for the tractor and trailer, respectively $\left(\mathrm{m} / \mathrm{s}^{2}\right)$. In this case, the variations in the camber angle caused by body roll and lateral forces can be calculated using [21]

$$
\left\{\begin{array}{l}
\gamma_{1}=\frac{M_{\phi_{1}}}{\varphi_{1}} \Gamma_{11}+F_{Y_{1}} \Gamma_{12} \\
\gamma_{2}=\frac{M_{\phi_{1}}}{\varphi_{1}} \Gamma_{21}+F_{Y_{2}} \Gamma_{22} \\
\gamma_{3}=\frac{M_{\phi_{2}}}{\varphi_{2}} \Gamma_{31}+F_{Y_{3}} \Gamma_{32}
\end{array}\right.
$$

where $\varphi_{1}$ and $\varphi_{2}$ are the roll stiffnesses of the tractor and trailer, respectively $(\mathrm{N} \cdot \mathrm{m} / \mathrm{rad}) ; \Gamma_{11}, \Gamma_{21}$, and $\Gamma_{31}$ are the variation ratios of the camber angle of the front, middle, and rear suspensions under roll conditions, respectively ( $\mathrm{rad} /$ rad); and $\Gamma_{12}, \Gamma_{22}$, and $\Gamma_{32}$ are the variation ratios for the camber angle of the front, middle, and rear suspensions under lateral force conditions, respectively $(\mathrm{rad} / \mathrm{N})$.

By simultaneously solving equations (8) and (9), the following is obtained:

$$
\left\{\begin{array}{l}
\gamma_{1}=m u \omega_{r_{1}}\left(\frac{h_{1}}{\varphi_{1}} \Gamma_{11}+\frac{b}{L_{1}} \Gamma_{12}\right)=m u \omega_{r_{1}} \Delta_{1}, \\
\gamma_{2}=m u \omega_{r_{1}}\left(\frac{h_{1}}{\varphi_{1}} \Gamma_{21}+\frac{a}{L_{1}} \Gamma_{22}\right)=m u \omega_{r_{1}} \Delta_{2}, \\
\gamma_{3}=m u \omega_{r_{2}}\left(\frac{h_{2}}{\varphi_{2}} \Gamma_{31}+\frac{a_{1}}{L_{2}} \Gamma_{32}\right)=m u \omega_{r_{2}} \Delta_{3} .
\end{array}\right.
$$

The relative rotational resistance moment at the hinge of the tractor and trailer can be calculated with equation (8) as

$$
M_{A}=C_{A} \dot{\theta},
$$

where $M_{A}$ is the relative rotational resistance moment at the hinge of the tractor and trailer and $C_{A}$ is the relative rotation damping coefficient.

By simultaneously solving equations (5)-(7), (10), and (11), the following is obtained:

$$
\left\{\begin{array}{l}
a_{11} \dot{\beta}_{1}+a_{12} \dot{\omega}_{r_{1}}+a_{13} \dot{\omega}_{r_{2}}+a_{14} \dot{\theta}+b_{11} \beta_{1} \\
+b_{12} \omega_{r_{1}}+b_{13} \omega_{r_{2}}+b_{14} \theta=c_{1} \delta \\
a_{21} \dot{\beta}_{1}+a_{22} \dot{\omega}_{r_{1}}+a_{24} \dot{\theta}+b_{21} \beta_{1}+b_{22} \omega_{r_{1}}=c_{2} \delta \\
a_{31} \dot{\beta}_{1}++a_{33} \dot{\omega}_{r_{2}}+b_{31} \beta_{1}+b_{32} \omega_{r_{1}}+b_{33} \omega_{r_{2}}+b_{34} \theta=c_{3} \delta,
\end{array}\right.
$$

where $\quad a_{11}=\left(m_{1}+m_{2}\right) u, \quad a_{12}=-m_{2} c, \quad a_{13}=-m_{2} a_{1}$, $a_{22}=I_{z_{1}}, a_{14}=-m_{2} u, a_{21}=m_{1} u c, a_{24}=C_{A}, a_{31}=m_{1} a_{1} u$, $a_{33}=I_{z_{2}}, a_{34}=-C_{A}, \quad b_{11}=k_{1}+k_{2}+k_{3}, b_{21}=\left(a_{1}+c\right) k_{1}-$ $(b-c) k_{2}, \quad b_{31}=a_{1}\left(k_{1}+k_{2}\right)-b_{1} k_{3}, \quad b_{21}=\left(a_{1}+c\right) k_{1}-(b-$ c) $k_{2}, \quad b_{14}=k_{3}, \quad b_{12}=\left(a k_{1}-b k_{2}-c k_{3}\right) / u+m_{1} u\left(1-C_{1} \Delta_{1}-\right.$ $\left.C_{2} \Delta_{2}\right), \quad b_{34}=-b_{1} k_{3}, \quad b_{22}=\left[a(a+c) k_{1}+b \quad(b-c) k_{2}\right] / u+$ $m_{1} u\left[c-(a+c) C_{1} \Delta_{1}-(b-c) C_{2} \Delta_{2}\right], b_{32}=\left[a_{1}\left(a k_{1}-b k_{2}\right)+\right.$ $\left.b_{2} c k_{3}\right] / u+m_{1} u a_{1}\left(1-C_{1} \Delta_{1}-C_{2} \Delta_{2}\right), b_{33}=b_{1}\left(b_{1}+a_{1}\right) k_{3} / u+$ $m_{2} u b_{1} C_{3} \Delta_{3}, c_{1}=k_{1}, c_{2}=(a+c) k_{1}$, and $c_{3}=a_{1} k_{1}$.

In equation (12), $[\delta]$ is the input vector and $[\mathbf{X}]=\left[\begin{array}{llll}\beta_{1} & \omega_{r_{1}} & \omega_{r_{2}} & \theta\end{array}\right]$ is the output vector. Equation (12) can be expressed in matrix form as

$$
\mathbf{A} \dot{X}+\mathbf{B X}=\mathbf{C} \boldsymbol{\delta},
$$

where $\mathbf{A}, \mathbf{B}$, and $\mathbf{C}$ are given by the matrices in equations (14)-(16), respectively:

$$
\begin{aligned}
& {[\mathbf{A}]=\left[\begin{array}{cccc}
a_{11} & a_{12} & a_{13} & a_{14} \\
a_{21} & a_{22} & a_{23} & 0 \\
a_{31} & 0 & a_{33} & a_{34} \\
0 & 0 & 0 & 1
\end{array}\right],} \\
& {[\mathbf{B}]=\left[\begin{array}{cccc}
b_{11} & b_{12} & b_{13} & b_{14} \\
b_{21} & b_{22} & 0 & 0 \\
b_{31} & b_{32} & b_{33} & b_{34} \\
0 & -1 & 1 & 0
\end{array}\right],}
\end{aligned}
$$




$$
[\mathbf{C}]=\left[\begin{array}{llll}
c_{1} & c_{2} & c_{3} & 0
\end{array}\right]^{T} .
$$

When the vehicle system is under steady-state steering conditions, it is considered that $\omega_{r_{1}}=\omega_{r_{2}}=\omega_{r}, \beta_{1}=\beta_{2}=\beta$, and $\theta$ are all approximately constant. In the differential equation system of equation (12), $\dot{\omega}_{r_{1}}=\dot{\omega}_{r_{2}}=0, \beta=0, \theta=0$. Then, the matrix form in equation (13) can be simplified as [22]

$$
\mathbf{B X}=\mathbf{C} \boldsymbol{\delta} \text {. }
$$

The yaw rate gain of the tractor and trailer and the relative rotation angle gain between them are obtained from solving the matrix equation as

$$
\left\{\begin{array}{l}
\frac{\omega_{r}}{\delta}=\frac{u}{L_{1}+K_{1} u^{2}}, \\
\frac{\theta}{\delta}=\frac{L_{1}+K_{1} u^{2}}{L_{2}+K_{2} u^{2}}, \\
\frac{\omega_{r}}{\theta}=\frac{u}{L_{2}+K_{2} u^{2}} .
\end{array}\right.
$$

2.4. Improved Method to Calculate the Stability Factor. A new method to calculate the stability factor can be obtained from equations (12) and (18) as follows. It is seen from equations (19) and (20) below that the roll torque and camber angle impact the stability factor, which affects the understeer of the entire vehicle [23]:

$$
K_{1}=\frac{m_{1}}{L_{1}}\left[\left(\frac{b}{k_{1}}-\frac{a}{k_{2}}\right)+A+B\right]+\frac{m_{2}}{L_{2}} \cdot \frac{b}{L_{1}}\left[\left(\frac{b-c}{k_{1}}-\frac{a+c}{k_{2}}\right)+C+D\right] \text {, }
$$

$$
K_{2}=\frac{m_{1}}{L_{1}}\left(\frac{a}{k_{2}}-E-F\right)+\frac{m_{2}}{L_{2}}\left(\frac{a+c}{L_{1}} \cdot \frac{b_{1}}{k_{2}}-\frac{a_{2}}{k_{3}}+G+H\right),
$$

where $A=\left(\left(a_{1} h_{1} / \varphi_{1}\right)\left(C_{2} / k_{2}\right) \Gamma_{21}\right)-\left(\left(b h_{1} / \varphi_{1}\right)\left(C_{1} / k_{1}\right) \Gamma_{11}\right)$, $B=\left(a^{2} / L_{1}\right)\left(C_{2} / k_{2}\right) \Gamma_{22}-\left(b^{2} / L_{1}\right)\left(C_{1} / k_{1}\right) \Gamma_{12}, C=(a+c) h_{1} /$ $\varphi_{1} \cdot C_{2} / k_{2} \Gamma_{21}-\left((b-c) h_{1} / \varphi_{1}\right)\left(C_{1} / k_{1}\right) \Gamma_{11}, D=\left(a(a+c) / L_{1}\right)$ $\left(C_{2} / k_{2}\right) \Gamma_{22}-\left(b(b-c) / L_{1}\right)\left(C_{1} / k_{1}\right) \Gamma_{12}, \quad E=\left(a h_{1} / \varphi_{1}\right)\left(C_{2} /\right.$ $\left.k_{2}\right) \Gamma_{21}, F=\left(a^{2} / L_{1}\right)\left(C_{2} / k_{2}\right) \Gamma_{22}, G=\left(a_{1} h_{2} / \varphi_{2}\right)\left(C_{3} / k_{3}\right) \Gamma_{31}-$ $\left((a+c) h_{1} / \varphi_{1}\right) \cdot\left(C_{2} / k_{2}\right) \Gamma_{21}$, and $H=\left(a_{1}^{2} / L_{2}\right)\left(C_{3} / k_{3}\right)$ $\Gamma_{32}-\left(a(a+c) / L_{1}\right) \cdot\left(C_{2} / k_{2}\right) \Gamma_{22}$.

The $A$ and $C$ ( $E$ and $G)$ values are the influence from changes in the tire camber angle of the tractor (trailer) as caused by body roll. The $B$ and $D(F$ and $H$ ) values are the influence from changes in the tire camber angle change of the tractor (trailer) caused by the lateral forces. Variations in the camber angle reduce the tire cornering stiffness and increase the tire sideslip angle and their differences $\left(\alpha_{1}-\alpha_{2}\right)$, which increases the vehicle's understeer.

\section{Yaw Rate Verification}

A MATLAB model was established to solve the dynamic state equation of the semitrailer system. The mathematical model considers body roll and changes in the camber angle as caused by roll and was used to compare the yaw rate as the evaluation index with the classical two-DOF linear model. Based on the vehicle parameters for three different types of semitrailer, two mathematical models for the handling and stability are calculated and compared with the real vehicle test data.

3.1. MATLAB Model. The MATLAB calculation model was established based on two mathematical models, as shown in appendix Figure 4. The MATLAB model was used to verify the mathematical model, and the calculation results for the two mathematical models are further compared. The model is verified based on the vehicle parameters for three different types of semitrailer, as shown in Table 1.

3.2. Experimental Verification. The yaw rate is an important indicator to describe the vehicle's transient response. The yaw rate evaluation index mainly evaluates the steady-state steering from the frequency domain. Lateral transient response tests were carried out according to the ISO 7401-2003 standard to further verify the accuracy of the proposed mathematical model for the entire vehicle [24]. The ISO 7401-2003 test method is more reasonable for equipment accuracy and test site and road requirements; the test method is more convenient and easy to operate, so this paper uses ISO 7401-2003 to verify the model. The vehicle was driven at a test speed of $80 \mathrm{~km} / \mathrm{h}$ in a straight line, where the initial speed should not deviate by more than $2 \mathrm{~km} / \mathrm{h}$. Starting from a $0 \pm 5 \%$ s yaw velocity equilibrium condition, a steering input is applied as rapidly as possible to a preselected value and maintained for several seconds after the measured vehicle motion variables have reached a steady state. This ensures the steering input is short relative to the vehicle response time. The time between $10 \%$ and $90 \%$ of the steering input should not be greater than $15 \mathrm{~s}$. The steeringwheel angle amplitude is determined from the steady-state driving on a circle with a radius that provides the preselected steady-state lateral acceleration (typically $6 \mathrm{~m} / \mathrm{s}^{2}$ ) at the required test speed. All test runs are performed at least three times. The steering wheel force and angle measuring instrument are shown in Figure 5(a), the gyroscope is shown in Figure 5(b), the GPS is shown in Figure 5(c), and the test road is shown in Figure 5(d).

3.3. Experimental Results. The lateral transient response tests indicate the simulation results using the mathematical model for the three different types of semitrailer are compared to the experimental yaw rate. To facilitate the research, this paper takes the calculation results for the tractor as an example for further comparisons and explanations, as shown in Table 2.

The results show that, for the yaw rat, the steady-state error is controlled to within $0.23 \%$, the peak error is controlled to within $0.28^{\circ} \mathrm{s}$, the overshoot error is controlled to within $1.9 \%$, and the response time error is controlled within $0.02 \mathrm{~s}$. The calculation results from the mathematical model, 


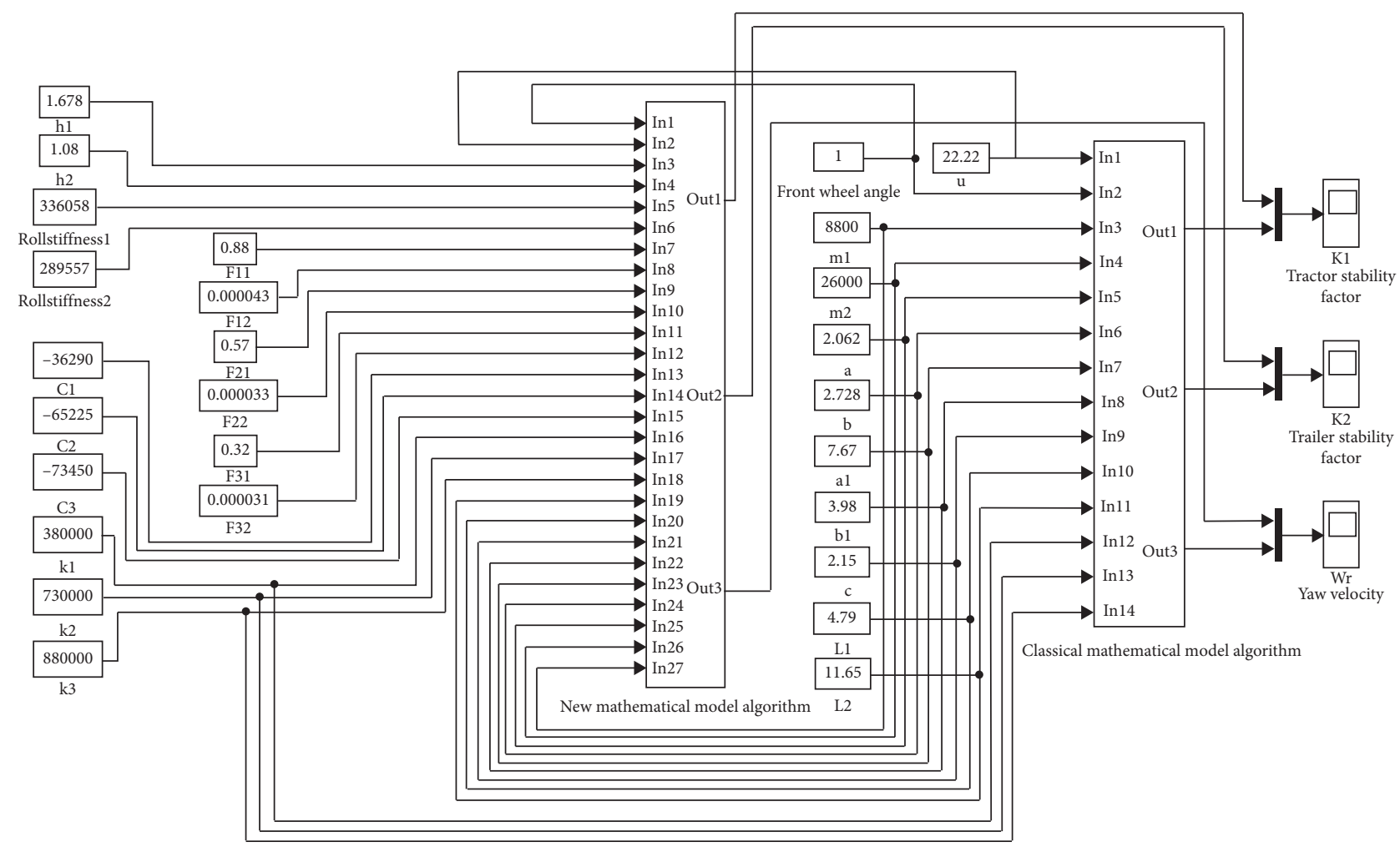

FIgURE 4: MATLAB solution model of two mathematical models.

TABLE 1: Vehicle parameter and symbol table.

\begin{tabular}{|c|c|c|c|}
\hline Parameter & Semitrailer I & Semitrailer II & Semitrailer III \\
\hline$m_{1}(\mathrm{~kg})$ & 8800 & 8439 & 4450 \\
\hline$m_{2}(\mathrm{~kg})$ & 26000 & 15000 & 9500 \\
\hline$a(\mathrm{~m})$ & 2.06 & 1.80 & 1.11 \\
\hline$b(\mathrm{~m})$ & 2.73 & 2.10 & 2.79 \\
\hline$a_{1}(\mathrm{~m})$ & 7.67 & 5.10 & 3.50 \\
\hline$b_{1}(\mathrm{~m})$ & 3.98 & 2.90 & 3.90 \\
\hline$c(\mathrm{~m})$ & 2.12 & 1.90 & 1.78 \\
\hline$L_{1}(\mathrm{~m})$ & 4.79 & 3.90 & 3.90 \\
\hline$L_{2}(\mathrm{~m})$ & 11.65 & 8.00 & 7.40 \\
\hline$I_{z 1}\left(\mathrm{~kg} \cdot \mathrm{m}^{2}\right)$ & 46100 & 18100 & 17650 \\
\hline$I_{z 2}\left(\mathrm{~kg} \cdot \mathrm{m}^{2}\right)$ & 200000 & 117400 & 105740 \\
\hline$k_{1}(\mathrm{~N} / \mathrm{rad})$ & 380000 & 544296 & 460000 \\
\hline$k_{2}(\mathrm{~N} / \mathrm{rad})$ & 730000 & 544296 & 460000 \\
\hline$k_{3}(\mathrm{~N} / \mathrm{rad})$ & 880000 & 681332 & 650000 \\
\hline$h_{1}(\mathrm{~m})$ & 1.678 & 1.28 & 1.02 \\
\hline$h_{2}(\mathrm{~m})$ & 1.08 & 0.92 & 1.84 \\
\hline$\varphi_{1}(\mathrm{Nm} / \mathrm{rad})$ & 336058 & 290000 & 345900 \\
\hline$\varphi_{2}(\mathrm{Nm} / \mathrm{rad})$ & 289557 & 269000 & 310000 \\
\hline$C_{1}(\mathrm{~N} / \mathrm{rad})$ & -36290 & -34625 & -37230 \\
\hline$C_{2}(\mathrm{~N} / \mathrm{rad})$ & -65225 & -43687 & -48520 \\
\hline$C_{3}(\mathrm{~N} / \mathrm{rad})$ & -73450 & -49856 & -69780 \\
\hline$\Gamma_{11}(\mathrm{rad} / \mathrm{rad})$ & 0.88 & 0.76 & 0.81 \\
\hline$\Gamma_{21}(\mathrm{rad} / \mathrm{rad})$ & 0.57 & 0.49 & 0.53 \\
\hline$\Gamma_{31}(\mathrm{rad} / \mathrm{rad})$ & 0.32 & 0.33 & 0.30 \\
\hline$\Gamma_{12}(\mathrm{rad} / \mathrm{N})$ & 0.000043 & 0.000044 & 0.000039 \\
\hline$\Gamma_{22}(\mathrm{rad} / \mathrm{N})$ & 0.000033 & 0.000035 & 0.000032 \\
\hline$\Gamma_{32}(\mathrm{rad} / \mathrm{N})$ & 0.000031 & 0.000033 & 0.000030 \\
\hline
\end{tabular}




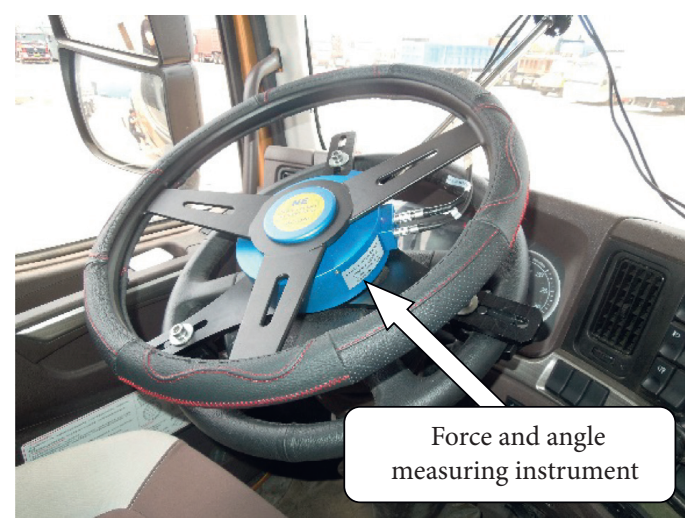

(a)

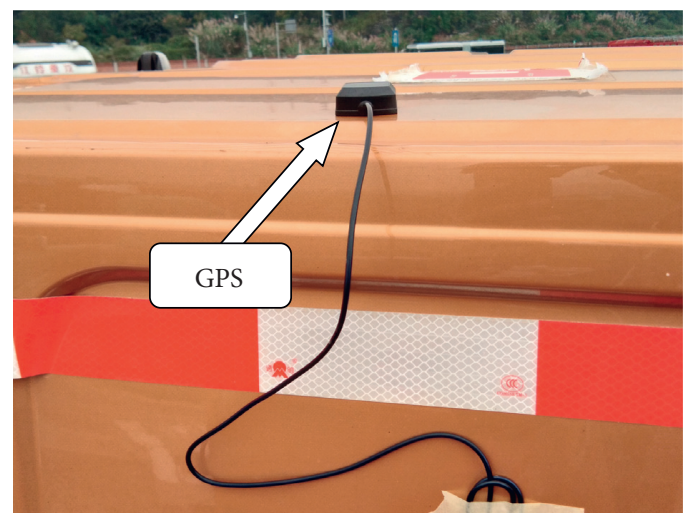

(c)

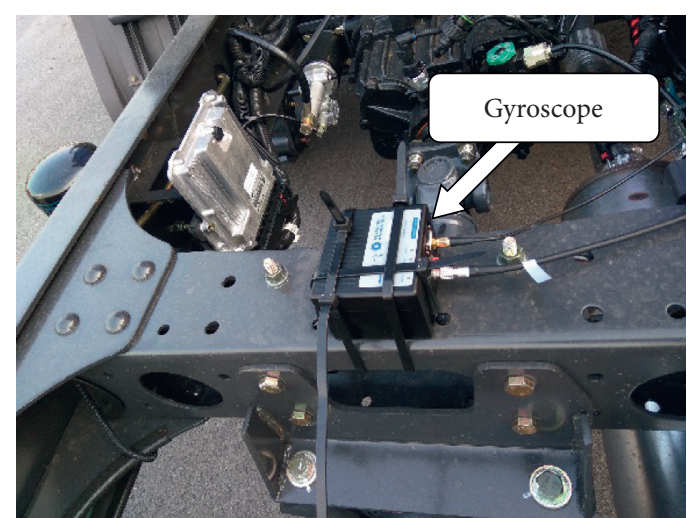

(b)

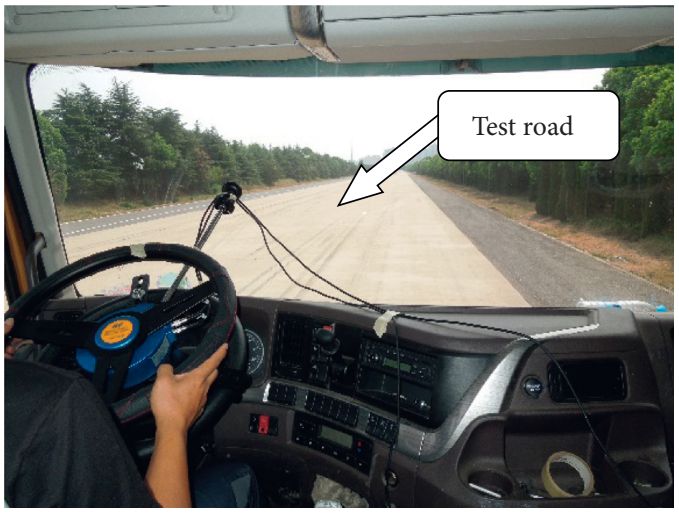

(d)

FIGURE 5: Experimental verification of the handling and stability for the semitrailer.

Table 2: Comparison of the yaw rate for different tractor types.

\begin{tabular}{|c|c|c|c|c|c|}
\hline Type & Parameter & Steady-state value $(\%)$ & Peak value $(\%)$ & Overshoot value (\%) & Response time (s) \\
\hline \multirow{3}{*}{ Semitrailer I } & Test & 9.35 & 12.62 & 34.9 & 0.23 \\
\hline & New model & 9.12 & 12.34 & 35.3 & 0.24 \\
\hline & Classic model & 13.05 & 14.0 & 7.3 & 0.13 \\
\hline \multirow{3}{*}{ Semitrailer II } & Test & 11.19 & 14.03 & 25.4 & 0.25 \\
\hline & New model & 11.04 & 14.05 & 27.3 & 0.27 \\
\hline & Classic model & 16.0 & 16.32 & 2.0 & 0.17 \\
\hline \multirow{3}{*}{ Semitrailer III } & Test & 11.43 & 12.06 & 5.5 & 0.21 \\
\hline & New model & 11.50 & 12.06 & 4.9 & 0.21 \\
\hline & Classic model & 13.46 & 14.02 & 4.2 & 0.15 \\
\hline
\end{tabular}

which considers body roll and the changes in the camber angle as caused by roll, agree well with the experimental data. However, the calculation result for the classical two-DOF model deviated greatly from the test data. A comparison of the yaw rates between the simulation and test data curves for the three different types of semitrailer is shown in Figure 6. Figures 7(a)-7(f) are plots of the yaw rates for the tractor and trailer for semitrailers I, II, and III, respectively. The following conclusions are based on Figure 6.

(i) The calculation curves of the mathematical model, which considers body roll and changes in the camber angle as caused by roll, are more consistent with the test curve with a higher calculation accuracy than the classical two-DOF model. (ii) When the wheel is turning, the vehicle body generates a roll, causing the inner and outer suspension springs to compress and extend, which is equivalent to the tire bouncing up and down. The camber angle of the tire changes in the negative direction, which is reflected in the yaw angular velocity response. The steady-state yaw rate calculated using the classical two-DOF model is generally higher than the test value due to the influence of the camber angle not being considered.

(iii) The response time, peak, and overshoot of the yaw rate calculated using the proposed model agree well with the experimental results, while the classical two-DOF model shows large distortions. 


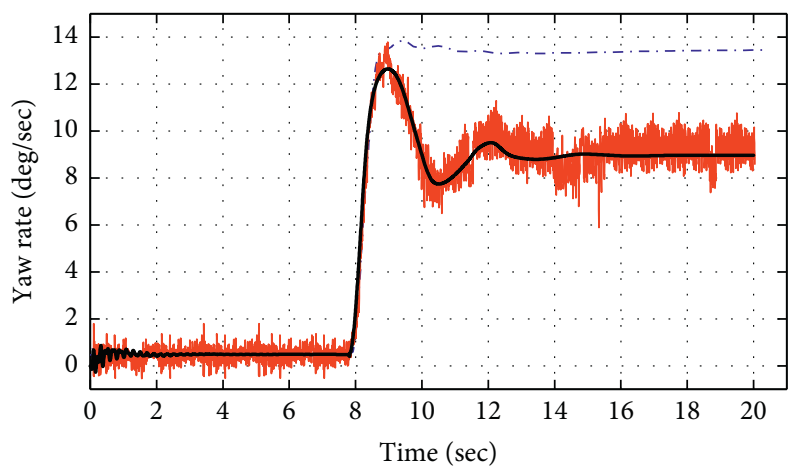

_ Mathematical model considering roll
_. Test data curve
_. Classical mathematical model

(a)



- Mathematical model considering roll Test data curve

-. . . Classical mathematical model

(c)



- Mathematical model considering roll

- Test data curve

-. - Classical mathematical model

(e)



- Mathematical model considering roll

- Test data curve

-. . . Classical mathematical model

(b)

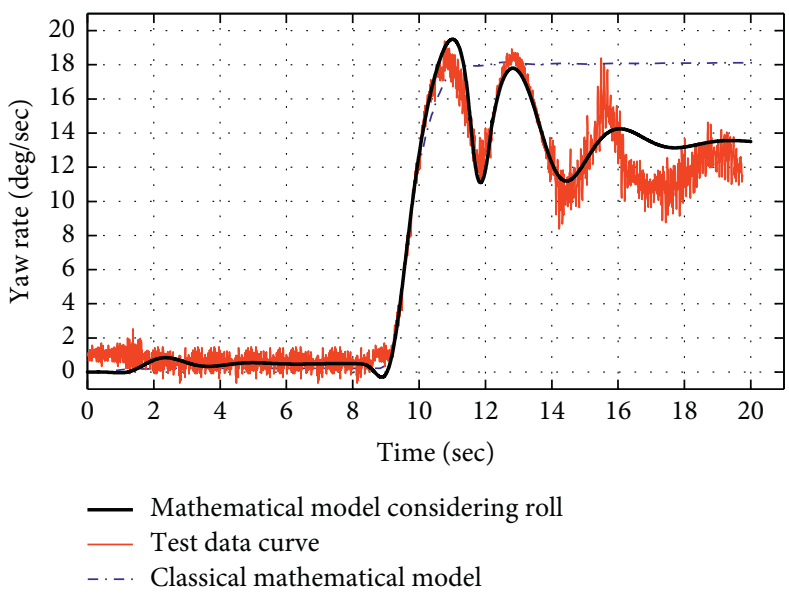

(d)

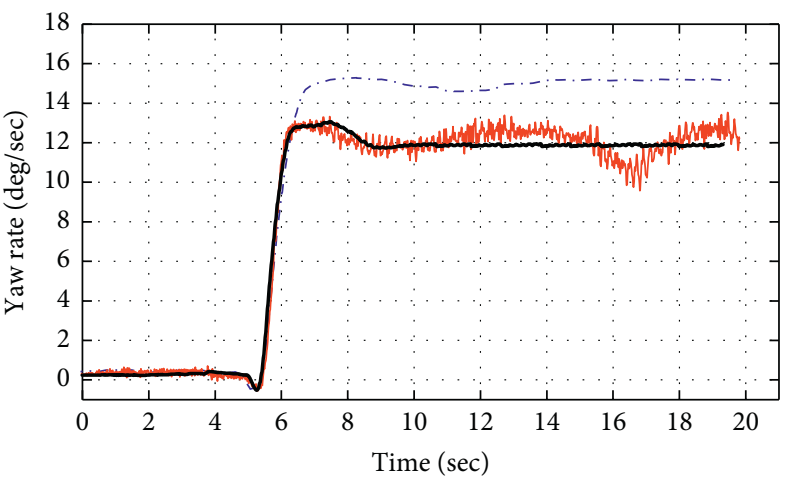

- Mathematical model considering roll

_ Test data curve

-. - Classical mathematical model

(f)

Figure 6: Comparison of the simulation and experimental test curves for the three different types of semitrailer. (a, b) Yaw rates of the tractor and trailer of semitrailer I, respectively. $(c, d)$ Yaw rates of the tractor and trailer of semitrailer II, respectively. (e, f) Yaw rates of the tractor and trailer of semitrailer III, respectively.

\section{Turning Radius Ratio Verification}

The relationship between the stability factor of the semitrailer and the turning radius ratio is derived. The proposed model was used to compare the turning radius ratio as the evaluation index with the classical two-DOF model. The vehicle parameters for three different types of semitrailer were used in the two mathematical models to calculate the 


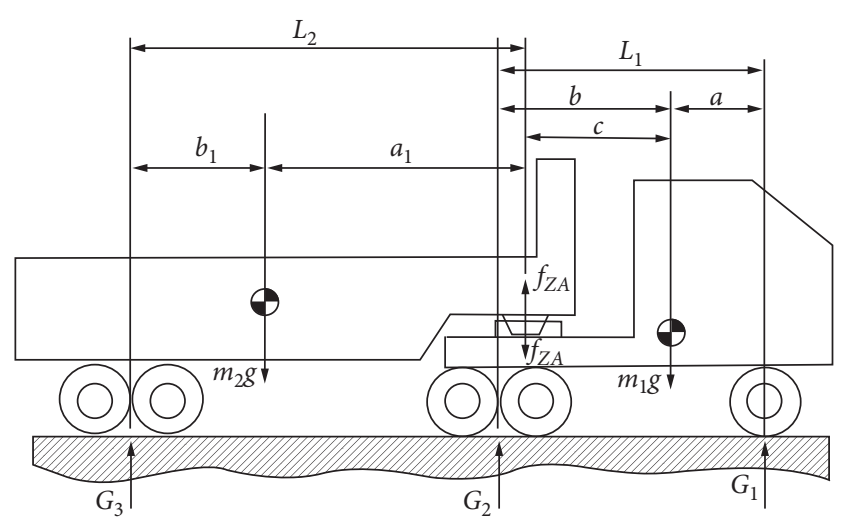

FIgURE 7: Schematic showing the load calculation and analysis.

handling and stability as compared with the real vehicle test data.

4.1. Calculation Model. The steady-state steering of the semitrailer can be characterised with the turning radius ratio. Therefore, the accuracy of the proposed model was verified by deriving the relationship between the stability factor and turning radius ratio.

As shown in Figure 7, the loads for each axle of the tractor and the trailer are calculated as

$$
\left\{\begin{array}{l}
G_{1}=\frac{1}{L_{1}}\left[b m_{1} g+(b-c) f_{Z A}\right] \\
G_{2}=\frac{1}{L_{1}}\left[a m_{1} g+(a+c) f_{Z A}\right] \\
G_{3}=\frac{a_{1}}{L_{2}} m_{2} g \\
f_{Z A}=\frac{b_{1}}{L_{2}} m_{2} g
\end{array}\right.
$$

where $G_{1}$ and $G_{2}$ are the front and middle axle loads $(\mathrm{N})$ and $f_{Z A}$ and $G_{3}$ are the saddle and rear axle loads $(\mathrm{N})$.

The calculation equations for $K_{1}$ and $K_{2}$ from Table 2 and equation (6) are expressed as

$$
\left\{\begin{array}{l}
K_{1}=\frac{1}{g}\left[\frac{G_{1}}{k_{1}}-\frac{G_{2}}{k_{2}}-\frac{G_{1} C_{1} \Delta_{1}}{k_{1}}+\frac{G_{2} C_{2} \Delta_{2}}{k_{2}}\right], \\
K_{2}=\frac{1}{g}\left[\frac{G_{2}}{k_{2}}-\frac{G_{3}}{k_{3}}-\frac{G_{2} C_{2} \Delta_{2}}{k_{2}}+\frac{G_{3} C_{3} \Delta_{3}}{k_{3}}\right] .
\end{array}\right.
$$

When the vehicle system enters steady-state steering, the lateral acceleration of each shaft is $a_{y}$, and the following equations can be obtained from equation (3) with $F_{Y i}=G_{i} a_{y i}$ :

$$
\left\{\begin{array}{l}
\alpha_{1}-\alpha_{2}=K_{1} M_{y} g \\
\alpha_{2}-\alpha_{3}=K_{2} M_{y} g
\end{array}\right.
$$

where $M_{y}=a_{y} / g$ and $g$ is the acceleration due to gravity $\left(\mathrm{m} / \mathrm{s}^{2}\right)$.

The distance from the traction pin of the semitrailer to the middle axle is relatively small, generally 50-200 mm [25]. The model is simplified so that the traction pin coincides with the middle axle. When there is no lateral deviation, $R_{01} \approx L_{1} / \delta$ and $R_{02} \approx L_{2} / \theta$; when there is a lateral deviation, $R_{1} \approx L_{1} /\left[\delta-\left(\alpha_{1}-\alpha_{2}\right)\right]$ and $R_{2} \approx L_{2} /\left[\theta-\left(\alpha_{2}-\alpha_{3}\right)\right]$. The theoretical equations to calculate the turning radius ratio are obtained by combining equation (8) with the above relationship as

$$
\left\{\begin{array}{l}
\frac{R_{1}}{R_{01}}=\frac{\delta}{\delta-K_{1} M_{y} g} \\
\frac{R_{2}}{R_{02}}=\frac{\theta}{\theta-K_{2} M_{y} g}
\end{array}\right.
$$

4.2. Experimental Verification. The understeer, neutral, and oversteer characteristics of an automobile are commonly referred to as the steady-state steering characteristics. The turning radius ratio $R / R_{0}$ is an important index used to characterize the steady-state steering characteristics of automobile. The tests for the steady-state circular driving behavior constant steering-wheel angle were performed based on the ISO 4138-2012 standard [26] test methods. The vehicle travels along a circle with a radius of $40 \mathrm{~m}(R=40 \mathrm{~m})$; the steering-wheel angle is fixed while the speed is increased continuously at a slow rate up to the limit of control. The test curve for semitrailer I and the turning radius ratio fit curve are shown in Figure 8 . The test curve and turning radius ratio of the tractor unit and the semitrailer units are shown in Figures 8(a)-8(d), respectively. As shown in Figure 8, the fit curve is consistent with the test data for $6.5 \mathrm{~m} / \mathrm{s}^{2}$, indicating the test data are reasonable. Therefore, the curves for the test and simulation calculations are compared and analysed within the data for lateral accelerations from 0 to $6.5 \mathrm{~m} / \mathrm{s}^{2}$. The test data of the other vehicle models are fit and processed using the same method.

4.3. Experimental Result. The curves for the test data after fitting are compared with the curves calculated using the proposed model, as shown in Figure 9. Figures 4(a)-4(f) are the turning radius ratio curve of the tractor and trailer of the semitrailers I, II, and III, respectively. Figure 9 provides the following conclusions.

(i) As shown in Figures 4(a)-4(d), the curve for the turning radius ratio of the proposed model is more consistent with the test curve than the classical twoDOF model. The trend of the understeer is also more consistent with the test curve, which indicates that changes in the camber angle weaken the lateral stiffness of the tire, increase the lateral deflection angle of the tire, and increase the difference $\left(\alpha_{1}-\alpha_{2}\right)$, thus enhancing the understeering of vehicles. 


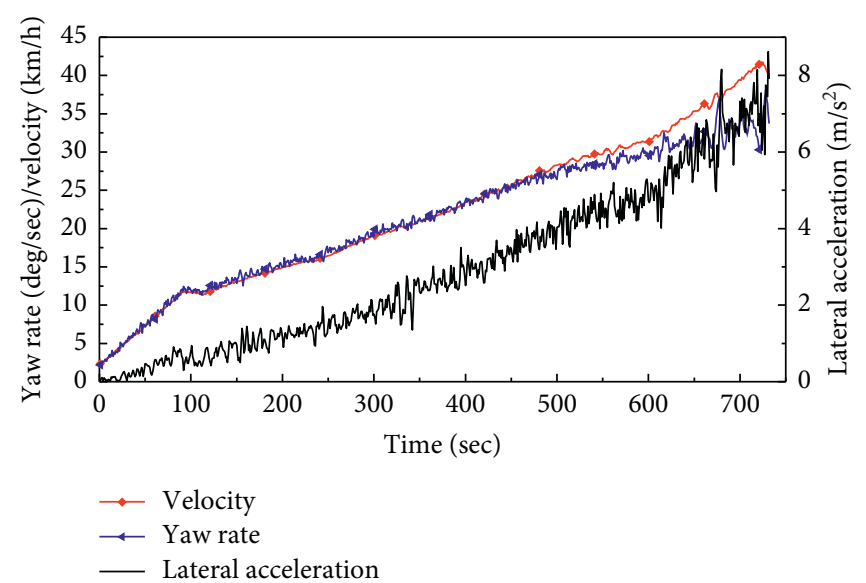

(a)

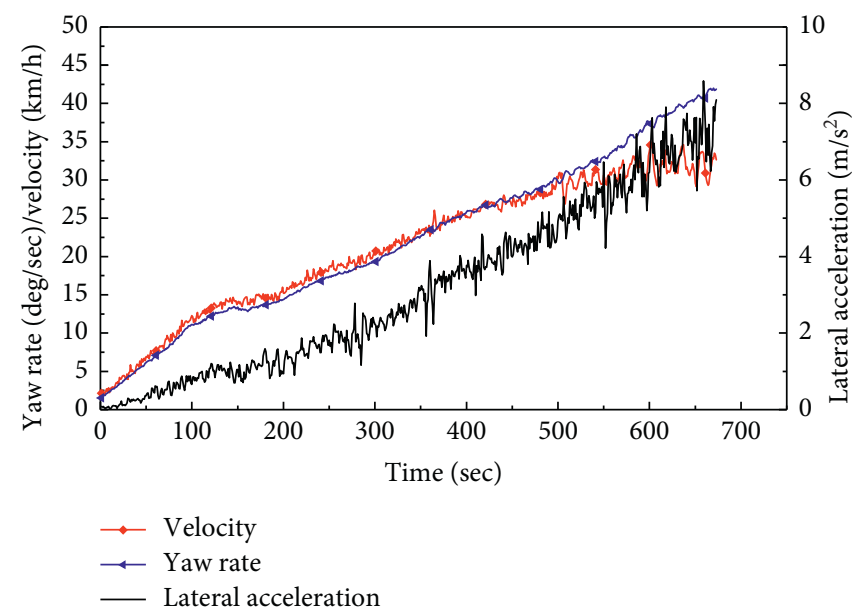

(c)

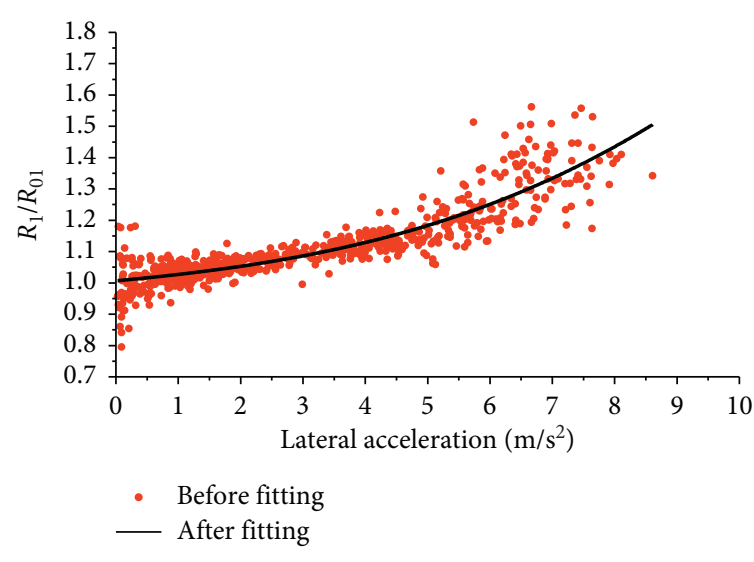

(b)

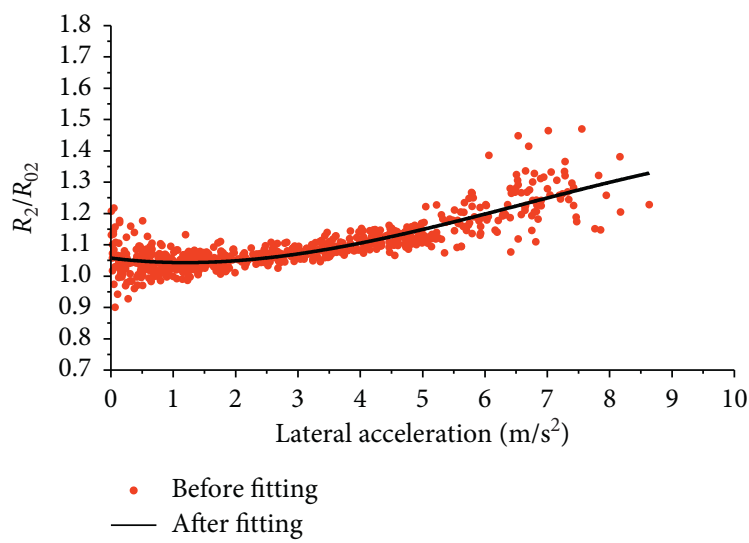

(d)

FIgURE 8: Semitrailer I test curve and the ratio of cornering radius.

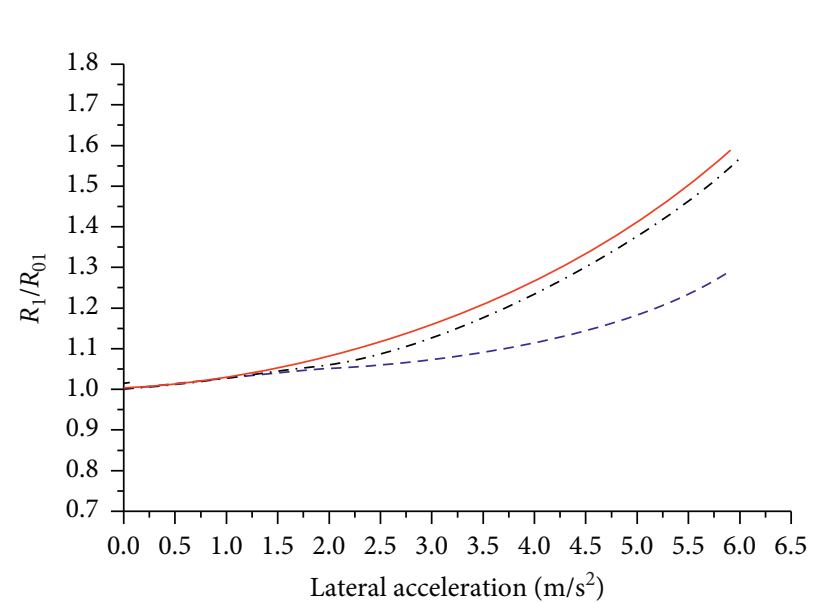

-. Mathematical model considering roll

- Test data curve

- - - Classical mathematical model

(a)

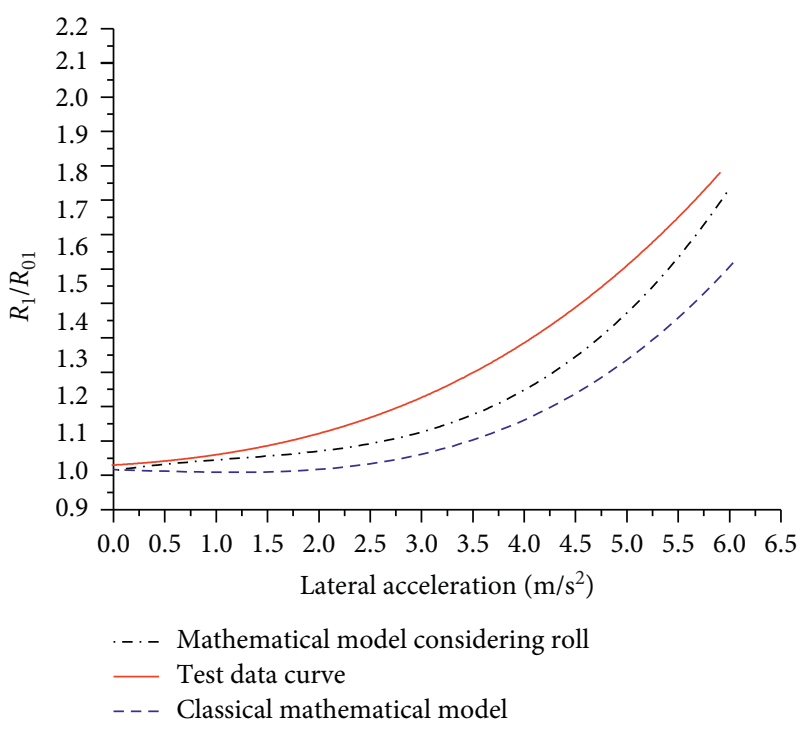

(b)

Figure 9: Continued. 


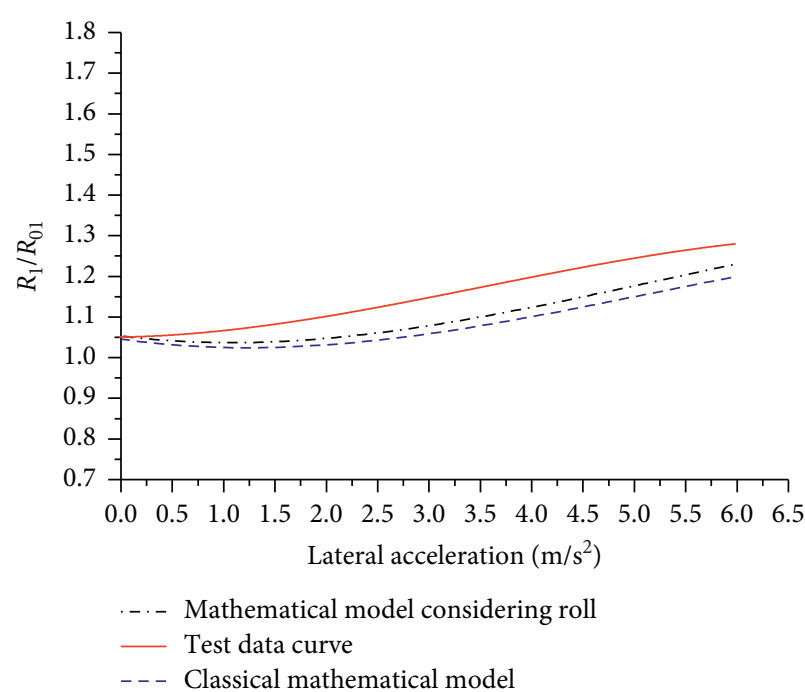

(c)

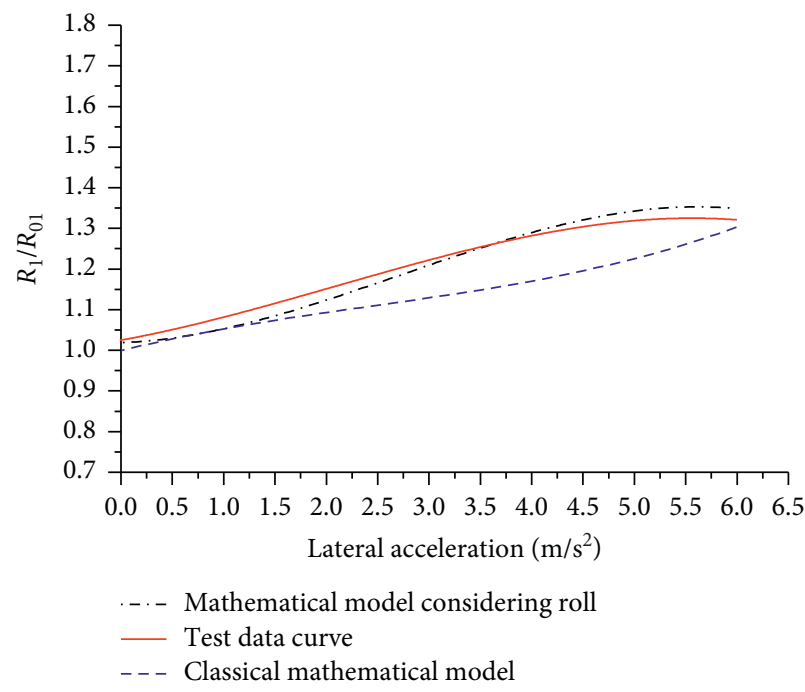

(e)

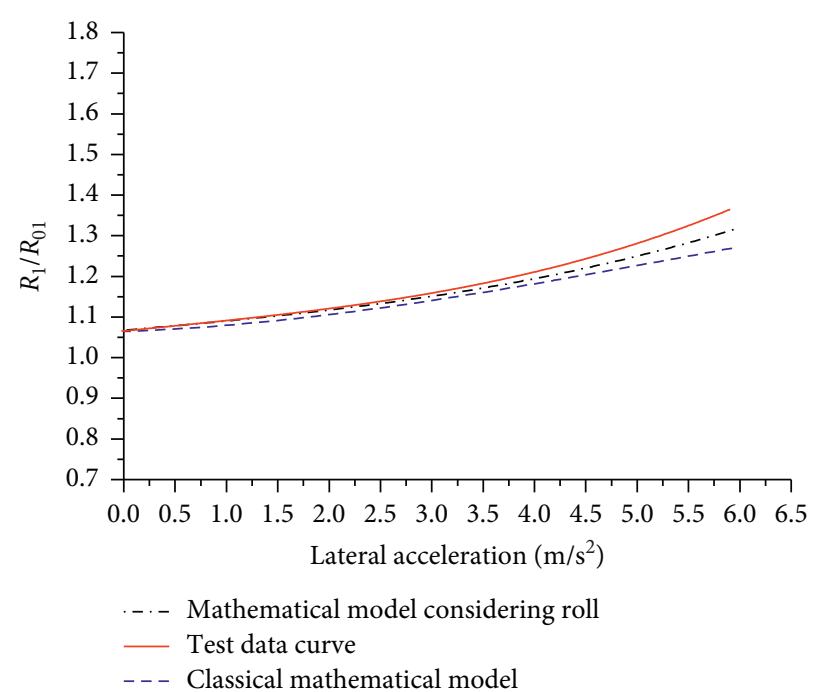

(d)

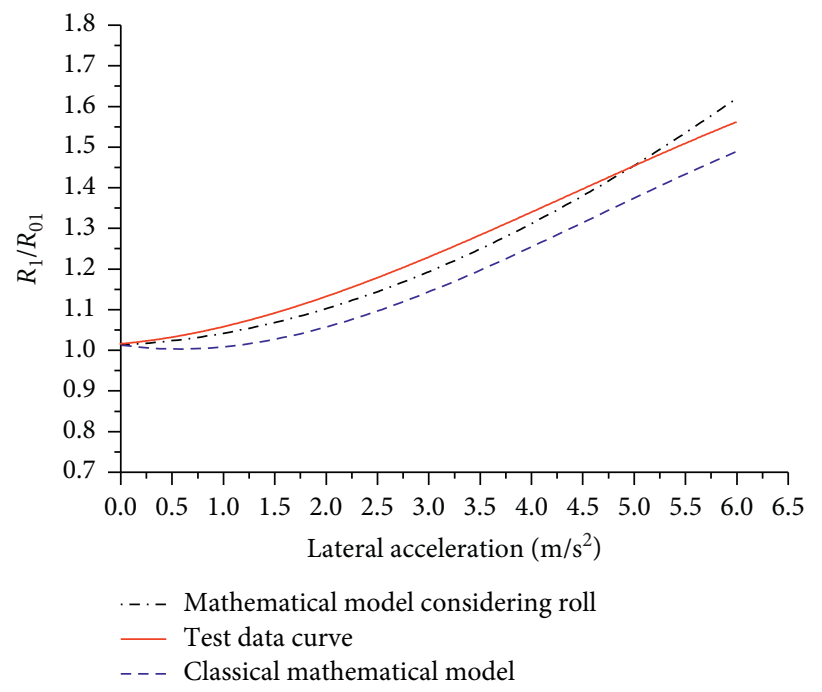

(f)

FIGURE 9: Curves for the turning radius ratio from the tests and simulations using the proposed and classical mathematical models. (a, b) Turning radius ratio of the tractor and trailer of semitrailer I, respectively. (c, d) Turning radius ratio of the tractor and trailer of semitrailer II, respectively. (e, f) Turning radius ratio of the tractor and trailer of semitrailer III, respectively.

(ii) As shown in Figure 9(e), when the lateral acceleration of the test curve for the tractor is $a_{y}=5.25 \mathrm{~m} / \mathrm{s}^{2}$, the vehicle begins to enter an understeer. When the lateral acceleration is $a_{y}=5.21 \mathrm{~m} / \mathrm{s}^{2}$, the proposed model considering roll begins to enter an understeer, which indicates that the calculation curve of the proposed model agrees well with the test curve.

\section{Conclusions}

This paper summarised the situations and shortcoming of modelling methods for handling and stability. Furthermore, the new modeling method is proposed. Body roll and the influence of the change of camber angle are introduced into the parameters of the mathematical model, and the dynamic equation of state is solved by MATLAB, and the results are compared with the classical linear mathematical model of the two DOF and the experimental results data. The conclusions are as follows:

(1) The calculation results for the proposed model, which considers body roll and changes in the camber angle caused by roll, are closer to the experimental values with a higher calculation accuracy than the classical two-DOF model.

(2) The proposed mathematical model provides a theoretical basis to design the structural parameters and improvement to handling stability of semitrailer.

(3) The proposed mathematical model considers the influence of changes in the camber angle as caused by roll but does not consider changes in the toe angle caused by roll, the influence of the kingpin 
inclination angle, or the influence of the K\&C characteristic parameters of the suspension. Thus, further studies can address the influence of these characteristic suspension parameters and further establish a more accurate dynamic equation for semitrailer trains.

\section{Appendix}

\section{Simulink Model}

The related Simulink models developed in the paper are illustrated in Figure 4.

\section{Data Availability}

The data used to support the findings of this study are available from the corresponding author upon request.

\section{Conflicts of Interest}

The authors declare that there are no conflicts of interest regarding the publication of this paper.

\section{Acknowledgments}

This research was financially supported by the Project of National Natural Science Foundation of China (Grant no. 51965013), the Science and Technology Major Project of Guangxi (Grant nos. AA18242033 and AA19182004), the Guangxi Key Laboratory of Manufacture System \& Advanced Manufacture Technology (Grant no. 17-259-05009Z), the Project of Guangxi Degree and Graduate Education Reform (Grant no. GJY2018061), the Guangxi Education Undergraduate Teaching Reform Project (Grant no.2018JGA161), the Guangxi Natural Science Foundation Program (Grant no.2018GXNSFBA281012), the GUET Excellent Graduate Thesis (Grant no. 17YJPYSS02), the Innovation Project of GUET Graduate Education (Grant no. 2019YCXS001), and the Innovation Project of Guangxi Graduate Education (Grant no. YCSW2020148).

\section{References}

[1] H. Termous, H. Shraim, R. Talj, C. Francis, and A. Charara, "Coordinated control strategies for active steering, differential braking and active suspension for vehicle stability, handling and safety improvement," Vehssicle System Dynamics, vol. 57, no. 10, pp. 1494-1529, 2019.

[2] H. Chen, X. Chen, C. Chen, Z. Peng, Y. Gong, and G. Chen, "Multidisciplinary design optimization for vehicle handling stability of steering-by-wire system," The Journal of Supercomputing, vol. 75, no. 6, pp. 2964-2985, 2019.

[3] W. Yang, X. Guan, and J. Zhang, "A recursive propagatorbased subspace method for vehicle handling dynamic system model identification," Proceedings of the Institution of $\mathrm{Me}$ chanical Engineers, Part D: Journal of Automobile Engineering, vol. 233, no. 3, pp. 495-516, 2019.

[4] W. Yang, P. Feng, and J. Zhang, "A comprehensive activesteering control method for improvement of vehicle handling performance," Proceedings of the Institution of Mechanical
Engineers, Part K: Journal of Multi-Body Dynamics, vol. 232, no. 3, pp. 413-425, 2018.

[5] S. D. Na, J. S. Jang, K. S. Kim, and W. S. Yoo, "Dynamic vehicle model for handling performance using experimental data," Advances in Mechanical Engineering, vol. 7, no. 11, 2015.

[6] D.-H. Wu, "A theoretical study of the yaw/roll motions of a multiple steering articulated vehicle," Proceedings of the Institution of Mechanical Engineers, Part D: Journal of Automobile Engineering, vol. 215, no. 12, pp. 1257-1265, 2001.

[7] T. Kobayashi, E. Katsuyama, H. Sugiura, E. Ono, and M. Yamamoto, "Direct yaw moment control and power consumption of in-wheel motor vehicle in steady-state turning," Vehicle System Dynamics, vol. 55, no. 1, pp. 104-120, 2017.

[8] S. Sankar and S. Surial, "A sensitivity analysis approach for fast estimation of rollover stability of heavy articulated vehicles during steady state turning," International Journal of Heavy Vehicle Systems, vol. 1, no. 3, pp. 282-303, 1994.

[9] Y. Zhang, J. Hu, and X. Li, "Steady-state characteristics of skid steering for wheeled vehicles," Proceedings of the Institution of Mechanical Engineers, Part D: Journal of Automobile Engineering, vol. 228, no. 9, pp. 1095-1104, 2014.

[10] K. Hussain, W. Stein, and A. J. Day, "Modelling commercial vehicle handling and rolling stability," Proceedings of the Institution of Mechanical Engineers, Part K: Journal of MultiBody Dynamics, vol. 219, no. 4, pp. 357-369, 2005.

[11] Z. Liu, K. Hu, and K.-w. Chung, "Nonlinear analysis of a closed-loop tractor-semitrailer vehicle system with time delay," Mechanical Systems and Signal Processing, vol. 76-77, pp. 696-711, 2016.

[12] V. G. Volkov, D. N. Demyanov, and V. S. Karabtsev, "Development and research of the mathematical model of planar motion of a vehicle with a semitrailer," Mathematical Models and Computer Simulations, vol. 10, no. 1, pp. 99-110, 2018.

[13] Y. Li, Q. Shi, and D. Qiu, "Parameter identification of tractorsemitrailer model under steering and braking," Mathematical Problems in Engineering, vol. 2019, Article ID 1345364, 14 pages, 2019.

[14] Y. Jiang, P. Wu, J. Zeng et al., "Researches on the resonance of a new type of suspended monorail vehicle-bridge coupling system based on modal analysis and rigid-flexible coupling dynamics," Vehicle System Dynamics, vol. 2019, pp. 1-20, 2019.

[15] F.-X. Xu, X.-H. Liu, W. Chen, C. Zhou, and . B.-W. Cao, "Improving handling stability performance of four-wheel steering vehicle based on the $\mathrm{H} 2 / \mathrm{H} \infty$ robust control," Applied Sciences, vol. 9, no. 5, p. 857, 2019.

[16] B. Lenzo, A. Sorniotti, P. Gruber, and K. Sannen, "On the experimental analysis of single input single output control of yaw rate and sideslip angle," International Journal of Automotive Technology, vol. 18, no. 5, pp. 799-811, 2017.

[17] Y. Wang, Z. Wei, and J. Yang, "Feature trend extraction and adaptive density peaks search for intelligent fault diagnosis of machines," IEEE Transactions on Industrial Informatics, vol. 15, no. 1, pp. 105-115, 2019.

[18] W. Zhao, X. Qin, and C. Wang, "Yaw and lateral stability control for four-wheel steer-by-wire system," IEEE/ASME Transactions on Mechatronics, vol. 23, no. 6, pp. 2628-2637, 2018.

[19] K. Alipour, A. B. Robat, and B. Tarvirdizadeh, "Dynamics modeling and sliding mode control of tractor-trailer wheeled mobile robots subject to wheels slip," Mechanism and Machine Theory, vol. 138, pp. 16-37, 2019.

[20] J. Yunta, D. Garcia-Pozuelo, V. Diaz, and O. Olatunbosun, "Influence of camber angle on tire tread behavior by an on- 
board strain-based system for intelligent tires," Measurement, vol. 145, pp. 631-639, 2019.

[21] D. Cao, B. Tang, H. Jiang, C. Yin, D. Zhang, and Y. Huang, "Study on low-speed steering resistance torque of vehicles considering friction between tire and pavement," Applied Sciences, vol. 9, no. 5, p. 1015, 2019.

[22] J. Loof, I. Besselink, and H. Nijmeijer, "Implementation and validation of a three degrees of freedom steering-system model in a full vehicle model," Vehicle System Dynamics, vol. 57, no. 1, pp. 86-107, 2019.

[23] B. Lenzo, F. Bucchi, A. Sorniotti, and F. Frendo, "On the handling performance of a vehicle with different front-to-rear wheel torque distributions," Vehicle System Dynamics, vol. 57, no. 11, pp. 1685-1704, 2019.

[24] ISO 7401-2011, Road Vehicles-Lateral Transient Response Test Methods-Open-Loop Test Methods.

[25] O. Chuanjin, Z. Gang, L. Xiandong, S. Yingchun, and D. Bin, "Simulation and analysis on handling stability of tractorsemitrailer," in Proceedings of the 2015 International Conference on Transportation Information and Safety (ICTIS), pp. 94-101, IEEE, Piscataway, NJ, USA, 2015.

[26] ISO-4138-2012, Road Vehicles-Steady-State Circular Driving Behaviour-Open-Loop Test Methods. 